\title{
EVALUATION OF SUBCHRONIC TOXICITY OF LACTOBACILLUS PARACASEI HIIO3 FERMENTED MORINDA CITRIFOLIA (NONI) FRUIT JUICE
}

\author{
CHAIYAVAT CHAIYASUT ${ }^{1 *}$, BHAGAVATHI SUNDARAM SIVAMARUTHI ${ }^{1}$, YODSAWEE DUANGJITCHAROEN ${ }^{2}$, \\ PERIYANAINA KESIKA ${ }^{1}$, SASITHORN SIRILUN ${ }^{1}$, KHONTAROS CHAIYASUT T ${ }^{3,4}$, SARTJIN PEERAJAN ${ }^{4}$
}

\begin{abstract}
${ }^{1}$ Innovation Center for Holistic Health, Nutraceuticals and Cosmeceuticals, Faculty of Pharmacy, Chiang Mai University, Chiang Mai-50200, Thailand. ${ }^{2}$ Division of Biopharmacy, Faculty of Pharmaceutical Sciences, Burapha University, Chonburi, Thailand. ${ }^{3}$ Institute of Research and Development, Chiang Mai Rajabhat University, Chiang Mai-50300, Thailand. ${ }^{4}$ Health Innovation Institute, Chiang Mai - 50200,

Thailand. Email: chaiyavat@gmail.com

Received: 21 June 2018, Revised and Accepted: 14 July 2018
\end{abstract}

ABSTRACT

Objective: The present study evaluated the subchronic toxicity of Lactobacillus paracasei mediated fermented Morinda citrifolia (Noni) juice (FMJ) using Sprague Dawley rat as a model system.

Methods: FMJ was prepared. The microbial load and $\mathrm{pH}$ of FMJ during fermentation were measured by a plating method and using $\mathrm{pH}$ meter, respectively. The healthy rats were supplemented with different doses of FMJ for 60 days. The changes in body weight of the animals were measured during FMJ intervention period. The blood and organs of the experimental rats were collected and were subjected to hematological and biochemical analysis by following standard hospital protocols, after the treatment period.

Results: After 30 days of fermentation, the pH of FMJ was reduced to 4.10 from 4.31. Lactobacillus load was increased gradually during fermentation while Bacillus spp. load decreased progressively, finally after 30 days of fermentation, no Bacillus spp., and yeast was found in FMJ. FMJ supplementation did not affect the body mass of experimental animals. The alternations in the organ weight were not associated with FMJ intervention. FMJ supplementation did not significantly affect the normal range of the selected hematological and biochemical parameters, which suggested that FMJ was not harmful to experimental rats.

Conclusion: FMJ was enriched with lactic acid bacteria, and free from pathogenic microbes. FMJ was found as safe for rodent consumption without any adverse effects. Further, studies are needed to explain the beneficial effect of $L$. paracasei mediated FMJ.

Keywords: Morinda citrifolia, Noni, Lactic acid bacteria, Subchronic Toxicity, Fermented plant juice.

(c) 2018 The Authors. Published by Innovare Academic Sciences Pvt Ltd. This is an open access article under the CC BY license (http://creativecommons. org/licenses/by/4. 0/) DOI: http://dx.doi.org/10.22159/ajpcr.2018.v11i11.28085

\section{INTRODUCTION}

Fermentation is a process of breakdown of the complex molecule into simple sugars, and it has a history of thousands of years. The fermentation is extensively used in food industries to improve the quality of the foods and preserve the foods. Many peoples, especially Asians, strongly believe that the consumption of fermented foods cures the several health discomforts and it has also been proved [1]. The fermentation process enhanced the free-radical scavenging activity and polyphenolic content of Phyllanthus emblica fruit juice [2]. The naturally fermented traditional foods are the source of several beneficial microbes, for example, $\gamma$-aminobutyric acid, glutamate decarboxylase, and glutaminase producing microbes were reported [3,4]. The lactic acid bacteria mediated fermented Hericium erinaceus juice was reported as a health supplement to improve the health status of diabetes patent [5].

Morinda citrifolia L. (Noni) belongs to the family of Rubiaceae, and majorly found in Malaysia, Borneo, Indonesia, and Australia. Noni fruit has been used as medicine and food for thousands of years [6]. Noni fruit juice (NFJ) has been traditionally used to treat inflammation, diabetes, and noni is eaten raw [7]. The roots and barks of the noni plant have been used as dyes. The various part of M. citrifolia plants such as fruits, leaves, roots, and bark has been reported for several health benefits such as anticancer, anti-infection, anti-inflammation, pro-inflammatory effects, antitubercular, nephroprotective, and antidiabetes [7-16].

Approximately, more than 200 bioactive compounds from noni have been reported [17]. Even though noni and its products were reported for beneficial effects, some of the controversial reports also are there $[18,19]$. Some studies evaluated the subchronic toxicity of various part of noni plant extracts [20-24]. There was no literature on safety and subchronic toxicity of fermented noni fruits. The present study explained the subchronic toxicity of Lactobacillus paracasei HII03 mediated fermented noni juice using a rat model system.

\section{METHODS}

Preparation of fermented $M$. citrifolia $L$. fruit juice (FMJ)

The water, M. citrifolia, and cane sugar were mixed in the ratio of 10:3:1, and pasteurized. Then, the medium was inoculated with $10 \%$ of $L$. paracasei HII03 and fermented for 30 days at room temperature.

\section{Evaluation of FMJ}

The changes in color, odor, and consistency of FMJ were monitored by organoleptic techniques $[2,25]$. The $\mathrm{pH}$ of FMJ was kinetically assessed using $\mathrm{pH}$ meter (Inola, pH level 2, Weilheim) [2]. The samples were collected at different time points of fermentation, and the microbial load of FMJ was estimated by spread plate method using specific media [4].

Animals, intervention, and sample collection

All the animal (in vivo) experiments were permitted by the Ethical Committee of the Faculty of Medicine, Chiang Mai University (Approved protocol no: $1 / 2552$ dated 23 June 2009). The rats (Sprague Dawley rats of 150-180 g in weight) needed for the experiments were purchased from National Laboratory Animal Center, Mahidol University, Thailand, and were randomly separated into four groups as follows: 
- Group 1: (Control): Typical laboratory food (commercial food no. C.P. 082, Perfect Companion Group Co., Ltd., Bangkok, Thailand) + water.

- Group 2: (Low dose or effective dose [ED]): Typical laboratory food + water $+1.2 \mathrm{~mL} / \mathrm{kg} /$ day of FMJ.

- Group 3: (High dose group; HD): Typical laboratory food + water + $9.0 \mathrm{~mL} / \mathrm{kg} /$ day of FMJ.

- Group 4: (Post-ED [PED]): Typical laboratory food + water + $1.2 \mathrm{~mL} / \mathrm{kg} /$ day of FMJ for 53 days (FMJ intervention was stopped before a week of animal sacrifice and testing).

The experimental rats were supplemented with FMJ for 60 days. After the intervention period, blood and internal organs were collected for the investigation.

Measurement of body mass, and valuation of hematological, and biochemical parameters

The body mass of rats during the experimental period was recorded using digital weighing balance. The changes in the weight were calculated as per the following formula.

Changes in body mass $=$ final weight - the initial weight of rat .

The weight of the brain, eyes, heart, lung, liver, spleen, stomach, kidneys, and adrenal gland of the experimental rats was measured. Hemoglobin, hematocrits, white blood cell count, lymphocyte, platelets, and red blood cell count, aminotransaminase, alanine aminotransaminase, alkaline phosphatase levels, and triglyceride, and cholesterol level of the experimental rats were determined at MT InterMed (Hosptial) Growth Diags Co., Ltd. Ching Mai, Thailand, as per the standard procedures.

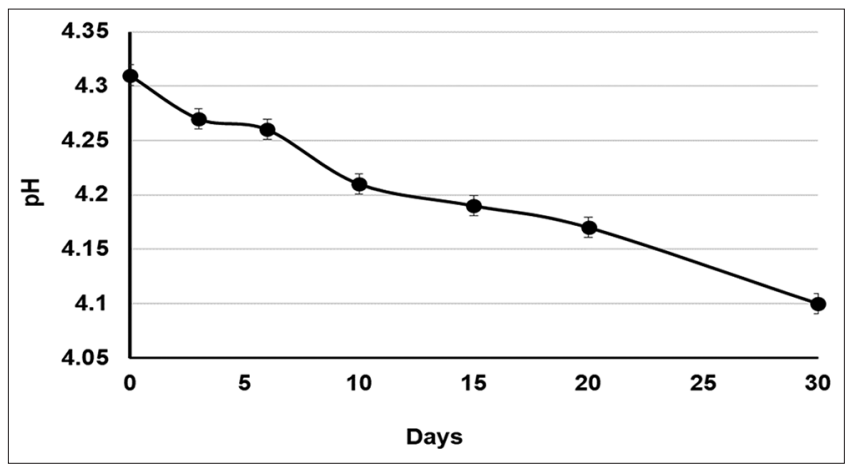

Fig. 1: The changes in the $\mathrm{pH}$ of fermented noni fruit juice

\section{Statistical analysis}

The experiments were performed in triplicate. The values were signified as a mean \pm standard deviation. Duncan's new multiple range tests determined the significant differences, at the $95 \%$ confidential level $(\mathrm{p}<0.05)$ by SPSS v.17 (Chicago, SPSS Inc, U.S.A).

\section{RESULTS AND DISCUSSION}

The noni fruit was fermented for 30 days, and the $\mathrm{pH}$ of the FMJ was decreased while the fermentation time increased. The initial $\mathrm{pH}$ of noni juice was 4.31, and the $\mathrm{pH}$ of fermented noni fruit was 4.10 (Fig. 1).

The specific bacterial fermentation facilitates the growth of starter culture. The microbial load of the FMJ has been increased gradually. The total bacterial count, and Lactobacillus spp. the content of FMJ was 11.67 , and $10.36 \log \mathrm{CFU} / \mathrm{mL}$, respectively. The microbial content was increased steadily without any decline until 30 days of fermentation. Bacillus spp. was observed in FMJ until 20 days of fermentation, but after 30 days, there were no live Bacillus cells detected. Yeast was not found in FMJ at any point of fermentation. The results suggested that the FMJ was rich in probiotic LAB strain and free from any harmful microbes; thus, FMJ was microbiologically safe (Fig. 2).

The average body mass of ED, HD, and PED group female rats after 60 days of FMJ intervention was $17.85 \pm 16.94,29.99 \pm 10.55$, and $23.57 \pm 7.56$ g, respectively. Likely, the male rats of ED, HD, and PED groups exhibited the weight of $87.00 \pm 16.90,97.86 \pm 20.68$, and $90.71 \pm 14.27 \mathrm{~g}$, respectively. The weight changes were significantly compared to respective controls. Body weight of all of the experimental animals groups after the first 7 days of the test showed statistical significance when compared to the control group of both sexes. Males were statistically significant but were lowered, whereas females did not statistically show significant differences from day 21 of the experiment. The past day of the test, weight gain of both sexes did not show statistically significant differences from the control group (Table 1).

After 60 days of FMJ supplementation, experimental rats were euthanized, and the organs such as heart, brain, eyes, liver, lungs, spleen, kidney, stomach, and adrenal glands were collected, weighed. The changes in the organ weight have been represented in Table 2. There were no significant changes observed in any of the organs of FMJ supplemented rats. The changes in hematological and biochemical parameters during FMJ intervention have been reported (Table 3), and those changes were not significantly affected the normal range of the selected parameters, which suggested that the supplementation of FMJ was not harmful to experimental rats.

The effect of supplementation NFJ in the immune system of the host has been reported in mice. The intervention of low concentration of NFJ

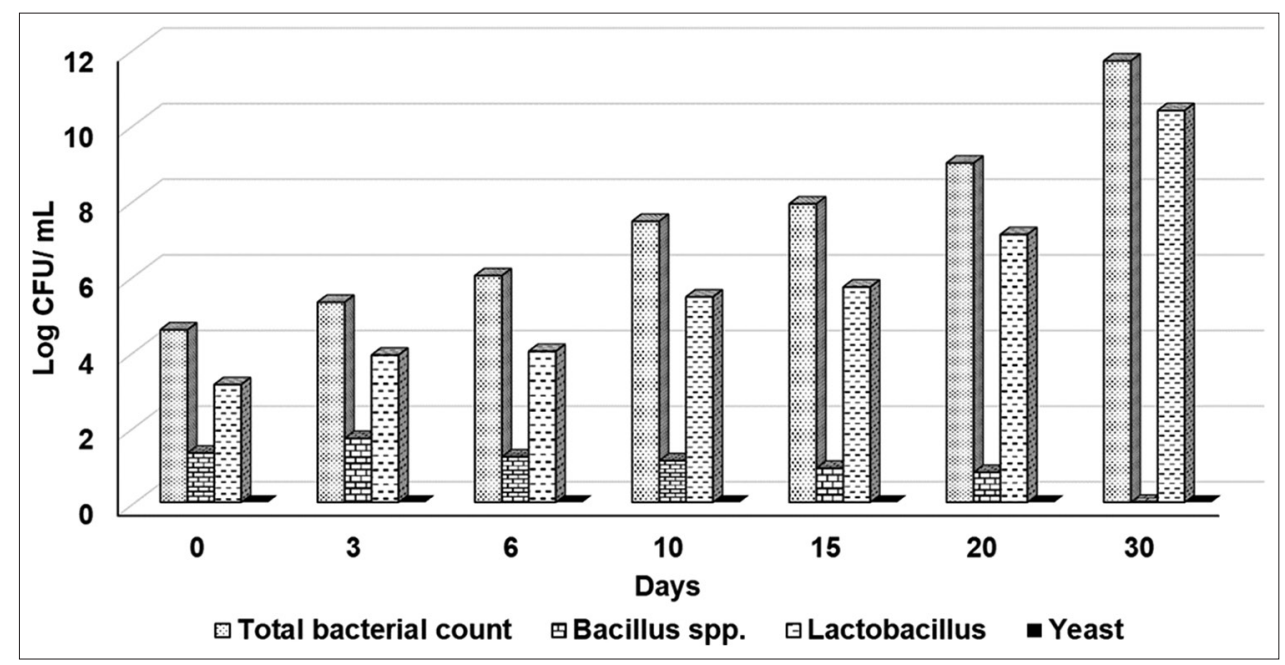

Fig. 2: Microbial load in noni fruit juice during fermentation 
Table 1: The body mass of test animals during the experimental period

\begin{tabular}{|c|c|c|c|c|c|c|c|c|}
\hline \multirow[t]{3}{*}{ Day } & \multicolumn{8}{|c|}{ Body weight (g) } \\
\hline & \multicolumn{4}{|l|}{ Male } & \multicolumn{4}{|l|}{ Female } \\
\hline & Control & ED* & HD $^{* *}$ & PED*** & Control & ED & HD & PED \\
\hline 7 & $26.67 \pm 13.66$ & $15.00 \pm 6.33^{\# \# \#}$ & $18.57 \pm 4.57^{\# \# \#}$ & $15.71 \pm 2.72^{\# \# \#}$ & $7.50 \pm 1.14$ & $9.28 \pm 1.38^{\# \# \#}$ & $9.29 \pm 1.42^{\# \#}$ & $9.26 \pm 4.56^{\#}$ \\
\hline 21 & $60.83 \pm 18.64$ & $40.00 \pm 9.79^{\#}$ & $46.43 \pm 10.38^{\# \#}$ & $37.86 \pm 6.04^{\# \#}$ & $23.33 \pm 6.58$ & $10.71 \pm 5.76$ & $18.57 \pm 8.93$ & $20.00 \pm 12.15$ \\
\hline 30 & $88.33 \pm 20.74$ & $56.43 \pm 10.56$ & $65.71 \pm 19.98^{\#}$ & $55.00 \pm 15.00$ & $29.17 \pm 12.81$ & $19.29 \pm 10.38$ & $17.86 \pm 6.44$ & $23.57 \pm 9.06$ \\
\hline 60 & $123.33 \pm 30.33$ & $87.00 \pm 16.90$ & $97.86 \pm 20.68$ & $90.71 \pm 14.27$ & $40.00 \pm 17.22$ & $17.85 \pm 16.94$ & $29.99 \pm 10.55$ & $23.57 \pm 7.56$ \\
\hline
\end{tabular}

*ED: $1.2 \mathrm{~mL} \mathrm{~kg} /$ day, ${ }^{* * H D}: 9 \mathrm{~mL} / \mathrm{kg} /$ day, ${ }^{* * *}$ PED: Post-effective dose (intervention has been stopped before 7 days of final assessments). ${ }^{\# S i g n i f i c a n t ~ d i f f e r e n c e ~(p<0.05) ~}$ between control and test-group, ${ }^{\#}$ significant difference $(\mathrm{p}<0.01)$ between control and test group, \#\# significant difference ( $\left.<<0.001\right)$ between control and test group, HD: High-dose

Table 2: Changes in the organ weight after oral supplementation of FMJ

\begin{tabular}{|c|c|c|c|c|c|c|}
\hline \multirow[t]{3}{*}{ Organs } & \multicolumn{6}{|l|}{ Weight (g) } \\
\hline & \multicolumn{3}{|l|}{ Male } & \multicolumn{3}{|l|}{ Female } \\
\hline & ED* & HD** & PED*** & ED & HD & PED \\
\hline Brain & $-0.13 \pm 0.25$ & $-0.07 \pm 0.07$ & $-0.04 \pm 0.16$ & $0.03 \pm 0.08$ & $0 \pm 0.09$ & $0.09 \pm 0.19$ \\
\hline Eyes & $0 \pm 0.02$ & $-0.02 \pm 0.04$ & $-0.01 \pm 0.03$ & $-0.01 \pm 0.03$ & $-0.04 \pm 0.06$ & $-0.01 \pm 0.02$ \\
\hline Heart & $0.14 \pm 0.43$ & $0.04 \pm 0.55$ & $0.18 \pm 0.37$ & $-0.12 \pm 0.29$ & $0.01 \pm 0.26$ & $-0.38 \pm 0.51$ \\
\hline Lung & $-0.28 \pm 0.52$ & $-0.13 \pm 0.36$ & $-0.06 \pm 0.38$ & $0.29 \pm 0.87$ & $0.01 \pm 0.46$ & $0.34 \pm 0.63$ \\
\hline Spleen & $-0.22 \pm 0.30$ & $-0.08 \pm 0.11$ & $-0.08 \pm 0.05$ & $-0.15 \pm 0.17$ & $-0.03 \pm 0.06$ & $-0.05 \pm 0.06$ \\
\hline Stomach & $-0.05 \pm 0.19$ & $0.22 \pm 0.22$ & $0.25 \pm 0.16$ & $0.29 \pm 0.18$ & $0.27 \pm 0.20$ & $0.15 \pm 0.45$ \\
\hline Kidneys & $-0.21 \pm 0.53$ & $-0.30 \pm 0.31$ & $0.03 \pm 0.26$ & $0.35 \pm 0.26$ & $0.17 \pm 0.19$ & $0.19 \pm 0.11$ \\
\hline Adrenal Grand & $-0.01 \pm 0.02$ & $-0.02 \pm 0.02$ & $-0.01 \pm 0.04$ & $0.03 \pm 0.02$ & $0.01 \pm 0.01$ & $0.02 \pm 0.02$ \\
\hline
\end{tabular}

The values were derived from the control values (the difference between control value and experimental value, after the experimental period) and were represented as a mean \pm standard deviation. *ED: $1.2 \mathrm{~mL} / \mathrm{kg} /$ day, ${ }^{* *} \mathrm{HD}: 9 \mathrm{~mL} / \mathrm{kg} /$ day, ${ }^{* * * P E D}$ : Post-effective dose, FMJ: Fermented M. citrifolia juice, HD: High-dose

Table 3: Effect of supplementation of FMJ on the hematological and biochemical parameters in hamster after 60 days of treatment

\begin{tabular}{|c|c|c|c|c|c|c|}
\hline \multirow[t]{2}{*}{ Parameters } & \multicolumn{3}{|l|}{ Male } & \multicolumn{3}{|l|}{ Female } \\
\hline & ED & HD & PED & ED & HD & PED \\
\hline \multicolumn{7}{|c|}{ Hematological parameters } \\
\hline $\mathrm{RBC}(\mathrm{M} \mu \mathrm{L})$ & $-0.78 \pm 0.26$ & $-0.67 \pm 0.35$ & $0.75 \pm 0.19$ & $-0.22 \pm 0.20$ & $-0.59 \pm 0.24$ & $-0.20 \pm 0.14$ \\
\hline WBC $(\mathrm{M} \mu \mathrm{L})$ & $-0.64 \pm 1.57$ & $-3.50 \pm 2.94$ & $1.78 \pm 1.79$ & $-0.15 \pm 0.34$ & $-0.16 \pm 0.12$ & $-0.17 \pm 0.08$ \\
\hline HGB (g/dL) & $2.28 \pm 2.28$ & $3.14 \pm 3.32$ & $3.85 \pm 2.26$ & $-9.60 \pm 4.01$ & $-4.31 \pm 3.96$ & $-4.88 \pm 2.02$ \\
\hline Hematocrits (\%) & $1.92 \pm 1.99$ & $0.78 \pm 3.45$ & $0.50 \pm 2.16$ & $-1.81 \pm 2.60$ & $-2.10 \pm 3.43$ & $-2.95 \pm 2.83$ \\
\hline PMNC & $-1.92 \pm 1.99$ & $-0.78 \pm 3.45$ & $-0.50 \pm 2.16$ & $1.81 \pm 2.60$ & $2.10 \pm 3.43$ & $2.957 \pm 2.83$ \\
\hline Lymphocyte & $-0.66 \pm 0.99$ & $0.23 \pm 1.56$ & $-0.76 \pm 2.73$ & $1.06 \pm 2.38$ & $-0.27 \pm 2.45$ & $-1.30 \pm 2.35$ \\
\hline Platelets & $0.37 \pm 0.25$ & $0.26 \pm 0.34$ & $0.34 \pm 0.19$ & $0.47 \pm 0.23$ & $0.85 \pm 0.35$ & $0.45 \pm 0.32$ \\
\hline \multicolumn{7}{|c|}{ Biochemical parameters } \\
\hline B.U.N. (mg/dL) & $-1.38 \pm 1.70$ & $-4.10 \pm 6.20$ & $-2.81 \pm 2.34$ & $-3.90 \pm 4.89$ & $-3.33 \pm 5.20$ & $-3.76 \pm 4.12$ \\
\hline Creatinine (mg/dL) & $-0.08 \pm 0.05$ & $-0.18 \pm 0.24$ & $-0.03 \pm 0.15$ & $-0.01 \pm 0.19$ & $0.03 \pm 0.20$ & $-0.05 \pm 0.15$ \\
\hline Cholesterol (mg/dL) & $-5.10 \pm 8.64$ & $-7.81 \pm 14.94$ & $-6.24 \pm 7.96$ & $-13.25 \pm 14.57$ & $-10.17 \pm 19.83$ & $-15.7 \pm 19.79$ \\
\hline $\mathrm{TG}(\mathrm{mg} / \mathrm{dL})$ & $11.04 \pm 12.93$ & $17.90 \pm 16.86$ & $4.19 \pm 4.04$ & $-3.0 \pm 15.73$ & $-4.0 \pm 17.78$ & $-10.50 \pm 7.62$ \\
\hline AST (IU/L) & $-37.43 \pm 52.52$ & $-65.71 \pm 28.23$ & $-36.00 \pm 28.48$ & $-50.29 \pm 31.69$ & $-34.33 \pm 34.05$ & $-36.00 \pm 28.45$ \\
\hline ALT (IU/L) & $-8.90 \pm 7.22$ & $-10.90 \pm 15.19$ & $-1.33 \pm 1.35$ & $0.54 \pm 2.78$ & $-7.46 \pm 1.42$ & $-14.31 \pm 6.41$ \\
\hline
\end{tabular}

reduced the intestinal expression of interleukin (IL-4) and IL-10 while high concentration increased the levels of IL-12, tumor necrosis factor (TNF- $\alpha$ ), and interferon-gamma (IFN- $\gamma$ ) in the intestine. The increased level of IL-4, 10,12, and 23, IFN- $\gamma$, and TNF- $\alpha$ was observed in the liver. The high concentration of NFJ caused mild edema in the intestine. The study suggested that the ingestion of a tested concentration of NFJ was safe [26].

Recently, Abu et al. reported the antitumor, subchronic toxicity, and immunoregulatory property of noni derived anthraquinone called, nordamnacanthal (ND). ND exhibited a cytotoxic effect on several breast cancer cells such as MCF-7, MDA-MB231, and 4T1. ND intervention does not cause any mortality and diminishes the development of 4T1 in mice. The results suggested that ND supplementation enhanced the immunity without any adverse effects [24].

The aqueous extract of M. citrifolia leaves (AEM) was studied for its genotoxicity and subchronic toxicity in mice. The genotoxicity was measured by determining the incidence of micronuclei in mice bone marrow cells. The results suggested that about $2000 \mathrm{mg} / \mathrm{kg}$ of AEM was non-toxic in mice. The changes in hemoglobin and leukocyte count were observed while no significant changes were observed in the histological analysis [22]. Westendorf et al. [27] also reported that NFJ does not have genotoxicity, the toxic compound, anthraquinones, and not present in noni juice. 
The dried noni fruit powder (2000 and $5000 \mathrm{mg} / \mathrm{kg}$ of body weight) was supplemented to rats along with normal laboratory feed for 13 weeks. The total protein content, spleen weight, and white blood cells count were significantly reduced in experimental rats. The hematological parameters were not affected significantly. The results suggested that even the high concentration of noni fruit powder $(5000 \mathrm{mg} / \mathrm{kg}$ body weight/day) was non-toxic in Sprague-Dawley rats [21]

The ethanolic extract of M. citrifolia fruit (up to $5000 \mathrm{mg} / \mathrm{kg}$ ) does not cause any toxic effects and mortality in rats. The biochemical, hematological, and histopathological parameters were not changed significantly. The study suggested that ethanolic extract of noni fruit was non-toxic [28]. Likely, several toxicity studies revealed that noni was not hepatotoxic, and it was not affected the embryo development $[20,29,30]$.

\section{CONCLUSION}

The present study concluded that L. paracasei HII03 mediated FMJ was non-toxic to experimental rat and also revealed that LAB mediated fermented noni juice do not have any significant impact on hematological and biochemical parameters of the rat model. Further studies help to explore the pharmacological importance of FMJ.

\section{ACKNOWLEDGMENT}

Authors thankfully acknowledge the Chiang Mai University grant (CMUgrant) for the support and also acknowledge the Faculty of Pharmacy, and Chiang Mai University, Thailand, for the necessary provision. All the authors wish to acknowledge the National Science and Technology Development Agency for the support.

\section{CONFLICTS OF INTEREST}

There are no conflicts of interests.

\section{AUTHORS' CONTRIBUTIONS}

CC involved in the study design and finalization of the manuscript. BSS and PK contributed to data analysis, manuscript preparation, and critical revision of the manuscript. YD, SS, KC, and SP are responsible for wet lab experiments. All the authors agree with the content of the manuscript.

\section{REFERENCES}

1. Chaiyasut C, Sivamaruthi BS, Makhamrueang N, Peerajan S, Kesika P. A survey of consumer' opinion about consumption and health benefits of fermented plant beverages in Thailand. Food Sci Technol Campinas 2018;38:299-309.

2. Peerajan S, Chaiyasut C, Sirilun S, Chaiyasut K, Kesika P, Sivamaruthi BS. Enrichment of nutritional value of Phyllanthus emblica fruit juice using the probiotic bacterium, Lactobacillus paracasei $\mathrm{HII} 01$ mediated fermentation. Food Sci Technol Campinas 2016;36:116-23.

3. Komatsuzaki N, Shima J, Kawamoto S, Momose H, Kimura T. Production of $\gamma$-aminobutyric acid (GABA) by Lactobacillus paracasei isolated from traditional fermented foods. Food Microbiol 2005;22:497-504.

4. Woraharn S, Lailerd N, Sivamaruthi BS, Wangcharoen W, Sirisattha S, Chaiyasut C. Screening and kinetics of glutaminase and glutamate decarboxylase producing lactic acid bacteria from fermented Thai foods. Food Sci Technol Campinas 2014;34:793-9.

5. Chaiyasut C, Woraharn S, Sivamaruthi BS, Kesika P, Lailerd N, Peerajan S. Lactobacillus fermentum HP3 mediated fermented Hericium erinaceus juice as a health promoting food supplement to manage diabetes mellitus. J Evid Based Integr Med 2018;23:1-9.

6. Wang MY, West BJ, Jensen CJ, Nowicki D, Su C, Palu AK, et al. Morinda citrifolia (Noni): A literature review and recent advances in noni research. Acta Pharmacol Sin 2002;23:1127-41.

7. Basar S, Uhlenhut K, Hogger P, Schone F, Westendorf J. Analgesic and anti-inflammatory activity of Morinda citrifolia L. (Noni) fruit. Phytother Res 2010;24:38-42.

8. Dussossoy E, Brat P, Bony E, Boudard F, Poucheret P, Mertz C, et al. Characterization, anti-oxidative and anti-inflammatory effects of Costa Rican noni juice (Morinda citrifolia L.). J Ethnopharmacol 2011:133:108-15.

9. Lee SY, Park SL, Hwang JT, Yi SH, Nam YD, Lim SI. Antidiabetic effect of Morinda citrifolia (Noni) fermented by cheonggukjang in KK-A(y) diabetic mice. Evid Based Complement Alternat Med 2012;2012:163280.

10. Gupta RK, Banerjee A, Pathak S, Sharma C, Singh N. Induction of mitochondrial mediated apoptosis by Morinda citrifolia (Noni) in human cervical cancer cells. Asian Pac J Cancer Prev 2013;14:237-42.

11. Huang HL, Ko CH, Yan YY, Wang CK. Antiadhesion and antiinflammation effects of noni (Morinda citrifolia) fruit extracts on AGS cells during Helicobacter pylori infection. J Agric Food Chem 2014;62:2374-83.

12. Suzuki M, Tung NH, Kwofie KD, Adegle R, Amoa-Bosompem M, Sakyiamah $\mathrm{M}$, et al. New anti-trypanosomal active tetracyclic iridoid isolated from Morinda lucida Benth. Bioorg Med Chem Lett 2015;25:3030-3

13. Mueller M, Puttipan R, Janngeon K, Unger FM, Viernstein H, Okonogi S. Bioactivities of the Thai medicinal and edible plants C. Cajan, M. citrifolia and O. americanum. Int J Pharm Pharm Sci 2015;7:237-40.

14. Huang C, Wei YX, Shen MC, Tu YH, Wang CC, Huang HC. Chrysin, abundant in Morinda citrifolia fruit water-EtOAc extracts, combined with apigenin synergistically induced apoptosis and inhibited migration in human breast and liver cancer cells. J Agric Food Chem 2016;64:4235-45.

15. Ali M, Mruthunjaya KB, Nandini CA, Nabeel KA, Manjula SN. Chemoprotective effect of noni (Morinda citrifolia L.) fruit juice against cisplatin-induced nephrotoxicity. Int J Pharm Pharm Sci 2016;8:105-10.

16. Mauliku NE, Hendro W, Saputro SH, Kristina TN. Anti-tubercular activity of extract and compounds of noni (Morinda citrifolia Linn). Int J Pharm Pharm Sci 2017;9:105-9.

17. Singh D. Morinda citrifolia L. (Noni): A review of the scientific validation for its nutritional and therapeutic properties. J Diabetes Endocrinol 2012;3:77-91.

18. Millonig G, Stadlmann S, Vogel W. Herbal hepatotoxicity: Acute hepatitis caused by a noni preparation (Morinda citrifolia). Eur J Gastroenterol Hepatol 2005; 17:445-7.

19. Stadlbauer V, Weiss S, Payer F, Stauber RE. Herbal does not at all mean innocuous: The sixth case of hepatotoxicity associated with Morinda citrifolia (noni). Am J Gastroenterol 2008;103:2406-7.

20. West BJ, Su CX, Jensen J. Prenatal toxicity test of Morinda citrifolia (noni) fruit. J Toxicol Sci 2008;33:647-9.

21. Rosly SM, Shanmugavelu S, Murugaiyah M, Hadijah H, Tarmizi SA, Noridayusni Y, et al. Subchronic oral toxicity study of Morinda citrifolia (Mengkudu) in Sprague Dawley rats. Pertanika J Trop Agric Sci 2011;34:341-9.

22. Lagarto A, Bueno V, Merino N, Piloto J, Valdés O, Aparicio G, et al. Safety evaluation of Morinda citrifolia (noni) leaves extract: Assessment of genotoxicity, oral short term and subchronic toxicity. J Intercult Ethnopharmacol 2013;2:15-22.

23. West BJ. Report of Morinda citrifolia chronic toxicity not applicable to commercial noni juice. Regul Toxicol Pharmacol 2017;88:360-1.

24. Abu N, Zamberi NR, Yeap SK, Nordin N, Mohamad NE, Romli MF, et al. Subchronic toxicity, immunoregulation and anti-breast tumor effect of nordamnacantal, an anthraquinone extracted from the stems of Morinda citrifolia L. BMC Complement Altern Med 2018;18:31.

25. Woraharn S, Lailerd N, Sivamaruthi BS, Wangcharoen W, Peerajan S, Sirisattha S, et al. Development of fermented Hericium erinaceus juice with high content of L-glutamine and L-glutamic acid. Int J Food Sci Technol 2015;50:2104-12.

26. de Sousa BC, Miguel CB, Rodrigues WF, Machado JR, da Silva MV, da Costa TA, et al. Effects of short-term consumption of Morinda citrifolia (Noni) fruit juice on mice intestine, liver and kidney immune modulation. Food Agric Immunol 2017;28:528-42.

27. Westendorf J, Effenberger K, Iznaguen H, Basar S. Toxicological and analytical investigations of noni (Morinda citrifolia) fruit juice. J Agric Food Chem 2007;55:529-37.

28. Zahi AK, Hamzah H, Hutheyfa S, Shaari MR, Sithambaram S, Othman HH. Acute and sub-acute dermal toxicity studies of Morinda citrifolia L. fruit extract in Sprague Dawley rats. Asian J Pharm Clin Res 2015;8:400-8.

29. West BJ, Jensen CJ, Westendorf J. Noni juice is not hepatotoxic. World J Gastroenterol 2006;12:3616-9.

30. West BJ, Su CX, Jensen J. Hepatotoxicity and subchronic toxicity tests of Morinda citrifolia (noni) fruit. J Toxicol Sci 2009;34:581-5. 